\title{
Influence of microbiological reports on physician's choice of antimicrobial treatment for susceptible pathogens
}

J. Cobo $\cdot$ J. Oliva $\cdot$ J. Sanz $\cdot$ J. M. Aguado •

J. L. Del Pozo • S. Moreno

Published online: 20 January 2009

(C) Springer-Verlag 2008

Erratum to: Eur J Clin Microbiol Infect Dis (2003)

\section{2:569-572}

DOI:10.1007/s10096-003-0978-3

The name of the author J. del Pozo was published incorrect.

The correct name is:

Jose L. Del Pozo

The online version of the original article can be found at http://dx.doi. org/10.1007/s10096-003-0978-3

J. Cobo $(\varangle) \cdot$ J. Oliva $\cdot$ S. Moreno

Servicio de Enfermedades Infecciosas, Hospital Ramón y Cajal,

Carretera de Colmenar Viejo,

$\mathrm{Km}$ 9,

28034 Madrid, Spain

e-mail: jcobo.hrc@salud.madrid.org

J. Sanz

Servicio de Medicina Interna, Hospital Príncipe de Asturias, Carretera Alcalá Meco s/n, 28805 Alcalá de Henares,

Madrid, Spain

J. M. Aguado

Unidad de Enfermedades Infecciosas, Hospital 12 de Octubre,

Carretera de Andalucía, Km 5,4,

28035 Madrid, Spain

\section{J. L. Del Pozo}

Servicio de Microbiología, Clínica Universitaria de Navarra,

Avenida de Pío XII 36,

31008 Pamplona, Spain 